\title{
Oximetry neither to prescribe long-term oxygen therapy nor to screen for severe hypoxaemia
}

\author{
Yves Lacasse $\mathbb{1}^{1,2}$, Sébastien Thériault ${ }^{1,3}$, Benoît St-Pierre ${ }^{2}$, Sarah Bernard ${ }^{1}$, Frédéric Sériès ${ }^{1}$, \\ Harold Jean Bernatchez ${ }^{1}$ and François Maltais ${ }^{1,2}$
}

${ }^{1}$ Research Center, Institut universitaire de cardiologie et de pneumologie de Québec - Université Laval, Québec, Canada. ${ }^{2}$ Respiratory Home Care Programme, Institut universitaire de cardiologie et de pneumologie de Québec - Université Laval, Québec, Canada. ${ }^{3}$ Dept of Molecular Biology, Medical Biochemistry and Pathology, Université Laval, Québec, Canada.

Corresponding author: Yves Lacasse (yves.lacasse@med.ulaval.ca)

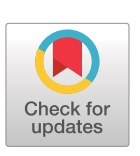

This version is distributed under the terms of the Creative Commons Attribution Non-Commercial Licence 4.0. For commercial reproduction rights and permissions contact permissions@ersnet.org

This article has supplementary material available from openres.ersjournals.com

Editorial comment in ERJ Open Res 2021; 7: 00495-2021 [https://doi.org/10.1183/ 23120541.00495-2021].

Received: 19 April 2021 Accepted: 23 July 2021

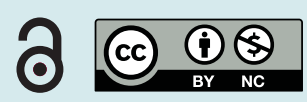

\section{Shareable abstract (@ERSpublications)}

Although transcutaneous pulse oximetry is widely used to diagnose severe hypoxaemia and prescribe long-term oxygen therapy in COPD, up to $40 \%$ of patients who qualify for this therapy would be denied treatment using the saturation threshold of $\leqslant 88 \%$ https://bit.ly/3jolWU5

Cite this article as: Lacasse Y, Thériault S, St-Pierre B, et al. Oximetry neither to prescribe long-term oxygen therapy nor to screen for severe hypoxaemia. ERJ Open Res 2021; 7: 00272-2021 [DOI: 10.1183/ 23120541.00272-2021].

\section{Abstract}

Background and objective Transcutaneous pulse oximetry saturation $\left(S_{\mathrm{pO}_{2}}\right)$ is widely used to diagnose severe hypoxaemia and to prescribe long-term oxygen therapy (LTOT) in COPD. This practice is not based on evidence. The primary objective of this study was to determine the accuracy (false positive and false negative rates) of oximetry for prescribing LTOT or for screening for severe hypoxaemia in patients with COPD.

Methods In a cross-sectional study, we correlated arterial oxygen saturation $\left(S_{\mathrm{aO}_{2}}\right)$ and $S_{\mathrm{pO}_{2}}$ in patients with COPD and moderate hypoxaemia $(n=240)$ and calculated the false positive and false negative rates of $S_{\mathrm{aO}_{2}}$ at the threshold of $\leqslant 88 \%$ to identify severe hypoxaemia (arterial oxygen tension $\left(P_{\mathrm{aO}_{2}}\right) \leqslant 55 \mathrm{mmHg}$ or $P_{\mathrm{aO}_{2}}<60 \mathrm{mmHg}$ ) in 452 patients with COPD with moderate or severe hypoxaemia.

Results The correlation between $S_{\mathrm{aO}_{2}}$ and $\mathrm{S}_{\mathrm{pO}_{2}}$ was only moderate (intra-class coefficient of correlation: 0.43; $95 \%$ confidence interval: $0.32-0.53$ ). LTOT would be denied in $40 \%$ of truly hypoxaemic patients on the basis of a $S_{\mathrm{aO}_{2}}>88 \%$ (i.e., false negative result). Conversely, LTOT would be prescribed on the basis of a $S_{\mathrm{aO}_{2}} \leqslant 88 \%$ in $2 \%$ of patients who would not qualify for LTOT (i.e., false positive result). Using a screening threshold of $\leqslant 92 \%$, $5 \%$ of severely hypoxaemic patients would not be referred for further evaluation.

Conclusions Several patients who qualify for LTOT would be denied treatment using a prescription threshold of saturation $\leqslant 88 \%$ or a screening threshold of $\leqslant 92 \%$. Prescription of LTOT should be based on $P_{\mathrm{aO}_{2}}$ measurement.

\section{Introduction}

Two landmark trials conducted $>40$ years ago provided scientific evidence that long-term oxygen therapy (LTOT) may prolong life [1, 2]. These two trials targeted patients with COPD and severe daytime hypoxaemia documented by direct arterial blood gas (ABG) measurement. The inclusion criteria of both studies still serve as current indications for LTOT in COPD, with minor variations worldwide [3].

In several jurisdictions, LTOT is actually prescribed and reimbursed on the basis of the measurement of oxygen saturation by transcutaneous pulse oximetry $\left(S_{\mathrm{pO}_{2}}\right)$ alone. For instance, in the United States, clinicians may use either a partial pressure of oxygen in arterial blood $\left(P_{\mathrm{aO}_{2}}\right) \leqslant 55 \mathrm{mmHg}$ or a $S_{\mathrm{pO}_{2}} \leqslant 88 \%$ (or a $P_{\mathrm{aO}}$ of 56 to $59 \mathrm{mmHg}$, or $S_{\mathrm{pO}_{2}}$ of $89 \%$ with evidence of cor pulmonale or erythrocythaemia) at rest in establishing severe hypoxaemia [4]. The authors of the recently published American Thoracic Society clinical practice guidelines for home oxygen therapy in adults with chronic lung disease recognised the limitations of $S_{\mathrm{pO}_{2}}$ for oxygen prescription. Nevertheless, the panel supported its use to "improve the 
usability of the guideline report in circumstances in which ABG measurements (are) not available” [5]. In Canada, the use of $S_{\mathrm{pO}_{2}}$ as a criterion for funding is inconsistent among provinces [6]. Although convenient, the practice of using pulse oximetry to determine the need for LTOT is not based on clinical evidence. The most recent British Thoracic Society guidelines for home oxygen use in adults suggested that pulse oximetry may be used for screening patients who might be candidates for LTOT. The guidelines recommend that patients with a resting stable saturation measured by transcutaneous pulse oximetry $\left(S_{\mathrm{pO}_{2}}\right)$ $\leqslant 92 \%$ should be referred for ABG assessment in order to assess eligibility for LTOT [7]. A good practice is also to elevate this threshold to $\leqslant 94 \%$ if end-organ damage (cor pulmonale or erythrocythaemia) is noted [7].

$S_{\mathrm{aO}_{2}}$ and $P_{\mathrm{aO}_{2}}$ are predictably related from the oxygen-haemoglobin dissociation curve. Although clinicians often use $S_{\mathrm{pO}_{2}}$ as a substitute for $S_{\mathrm{aO}_{2}}$, several studies reported that $S_{\mathrm{aO}_{2}}$ and $S_{\mathrm{pO}_{2}}$ are only moderately correlated [8-10]. Consequently, $S_{\mathrm{pO}_{2}}$ may not be as reliable as measuring $P_{\mathrm{aO}}$ to establish the presence of hypoxaemia [11]. By using pulse oximetry alone for LTOT prescription, clinicians and patients should be aware of the potential for misclassification, that is denying LTOT in truly hypoxaemic patients on the basis of a $S_{\mathrm{pO}_{2}}>88 \%$ (i.e., false negative result), or prescribing LTOT on the basis of a $S_{\mathrm{pO}_{2}} \leqslant 88 \%$ in patients who would not qualify for LTOT if ABG were actually measured (i.e., false positive result). Accordingly, our primary objectives were: 1) to demonstrate the correlation between $S_{\mathrm{pO}_{2}}$ and $S_{\mathrm{aO}_{2}}$; and 2) to determine the false positive and false negative rates of LTOT prescriptions in patients with COPD if it was based on $S_{\mathrm{aO}_{2}}$ alone. A secondary objective was to determine the $S_{\mathrm{aO}_{2}}$ thresholds at which the indication of LTOT can be ruled in or ruled out.

Material and methods

Design and patients

In a cross-sectional study, the results of ABG obtained from three separate groups of patients were analysed. First, we extracted the results of baseline ABGs of patients who participated in the International Nocturnal Oxygen (INOX) trial, a 4-year, multicentre, randomised, placebo-controlled trial of nocturnal oxygen therapy in patients with COPD [12]. To be included in the trial, patients had to have nocturnal oxygen desaturation without qualifying for LTOT. These patients usually have moderate hypoxaemia at rest (i.e., $P_{\mathrm{aO}}$ approaching the threshold of LTOT prescription [13]). ABGs were available in 240 of 243 patients who were randomised in the INOX trial (Cohort 1). Arterial blood was drawn from patients in sitting position. As per protocol, $S_{\mathrm{pO}_{2}}$ was also measured within 1 hour of arterial blood sampling using PalmSAT 2500 ${ }^{\mathrm{TM}}$ oximeter only (Nonin Medical Inc., Plymouth, MN, USA).

Second, we obtained from the respiratory home care programme of the Quebec City area (province of Quebec, Canada) the result of the ABG of patients registered in the programme as of January 1, 2015 with a main diagnosis of COPD who were prescribed LTOT (Cohort 2; $n=212$ ). To be admitted to the programme, severe hypoxaemia $\left(P_{\mathrm{aO}_{2}} \leqslant 55 \mathrm{mmHg}\right.$ or $P_{\mathrm{aO}_{2}}$ in the range of 56 to $59 \mathrm{mmHg}$ with clinical evidence of cor pulmonale or erythrocythaemia [1]) must be strictly demonstrated in stable condition. Patients were not allowed in the programme on the basis of $S_{\mathrm{pO}_{2}}$ alone, so that $S_{\mathrm{pO}_{2}}$ was not recorded in this cohort.

We also retrieved from the laboratory of biochemistry of our institution the results of all consecutive ABGs measured between January 2009 and June 2017 in outpatients or inpatients while breathing room air (Cohort 3; $n=848$ ). ABG of patients in an intensive care unit or in the recovery room, or those receiving supplemental oxygen were therefore excluded. Each patient contributed only one sample of arterial blood. The underlying diagnoses and indication of $\mathrm{ABG}$ measurement were irrelevant to the objectives of this study.

\section{Measurements}

Modern blood gas analysers measure $P_{\mathrm{aO}}$ using an amperometric electrode and $S_{\mathrm{aO}_{2}}$ using spectrophotometry [14]. $S_{\mathrm{aO}_{2}}$ is obtained by dividing the concentration of oxyhaemoglobin by the sum of the concentrations of oxyhaemoglobin and deoxyhaemoglobin in the sample. Patients in Cohorts 1 and 2 came from several locations, and ABGs were analysed using different blood gas analysers across institutions. In Cohort 3, all ABGs were analysed on an ABL 800 Flex blood gas analyser (Radiometer, Copenhagen, Denmark). Patient temperature was not noted; in all measurements it was assumed to be $37^{\circ} \mathrm{C}$.

\section{Patient and public involvement}

Patients were not directly involved in this study, which is a secondary analysis of data obtained from the INOX trial and a retrospective analysis of data kept in files at the respiratory home care programme of the 


\section{TABLE 1 Baseline characteristics}

\begin{tabular}{lccc} 
& $\begin{array}{c}\text { Cohort 1: patients with } \\
\text { COPD and isolated } \\
\text { nocturnal desaturation }\end{array}$ & $\begin{array}{c}\text { Cohort 2: patients } \\
\text { with COPD and } \\
\text { severe hypoxaemia }\end{array}$ & $\begin{array}{c}\text { Cohort 3: unselected } \\
\text { patients }\end{array}$ \\
\hline Subjects $n$ & 240 & 212 & 848 \\
\hline Age years & $69 \pm 8$ & $72 \pm 10$ & $72 \pm 12$ \\
Sex, male $n(\%)$ & $157(65 \%)$ & $97(46 \%)$ & $460(54 \%)$ \\
$P_{\mathrm{aO}_{2}} \mathrm{mmHg}$ & $67 \pm 7$ & $52 \pm 5$ & $57 \pm 10$ \\
$\mathrm{~S}_{\mathrm{aO}_{2} \%}$ & $93 \pm 2$ & $87 \pm 4$ & $89 \pm 5$ \\
$\mathrm{~S}_{\mathrm{pO}_{2} \%}$ & $93 \pm 2$ & $\mathrm{~N} / \mathrm{A}$ & $\mathrm{N} / \mathrm{A}$ \\
$P_{\mathrm{acO}_{2}} \mathrm{mmHg}$ & $42 \pm 6$ & $47 \pm 8$ & $44 \pm 8$ \\
$\mathrm{pH}$ & $7.42 \pm 0.03$ & $7.41 \pm 0.04$ & $7.43 \pm 0.04$ \\
\hline
\end{tabular}

Data expressed as mean \pm SD unless otherwise stated. $1 \mathrm{mmHg}=0.133 \mathrm{kPa} ; 1 \mathrm{kPa}=7.50 \mathrm{mmHg}$. N/A: not available. $P_{\mathrm{aO}_{2}}$ : arterial oxygen tension; $\mathrm{S}_{\mathrm{aO}_{2}}$ : arterial oxygen saturation; $\mathrm{S}_{\mathrm{pO}_{2}}$ : pulse oximetry saturation; $P_{\mathrm{aco}}$ : arterial carbon dioxide tension.

Quebec City area and at the laboratory of biochemistry of our institution. It received approval from the Research Ethics Committee of our institution (CER-IUCPQ-UL: 2021-3592, 22044).

\section{Statistics}

We used simple descriptive statistics (proportions, means and standard deviations, medians and interquartile ranges) throughout the study. Clinical characteristics of patients in the three cohorts were compared using chi-square tests for dichotomous variables and analyses of variance for continuous variables. We first correlated $S_{\mathrm{aO}_{2}}$ and $S_{\mathrm{pO}_{2}}$ in Cohort 1 using an intra-class coefficient of correlation (ICC) calculated from a two-way mixed effect model, with its 95\% confidence interval. We also assessed graphically the agreement between the two measures using a Bland-Altman diagram [15]. In the three cohorts, we then plotted $S_{\mathrm{aO}}$ against $P_{\mathrm{aO}}$ to represent oxygen-haemoglobin dissociation curves. We also cross-tabulated the results of $S_{\mathrm{aO}}$ and $\mathrm{P}_{\mathrm{aO}}$. In order to demonstrate the effect of arterial $\mathrm{pH}$ on the affinity of oxygen for haemoglobin [16], separate dissociation curves were also plotted after separating the cohorts into two groups at the median value of $\mathrm{pH}$ and summarised using local polynomial regression (locally estimated scatterplot smoothing [17]). By combining Cohort 1 and 2 (i.e., the two cohorts of patients with COPD), we calculated the false positive and false negative rates of $S_{\mathrm{aO}_{2}}$ at the thresholds of $\leqslant 88 \%$ (i.e., the American prescription threshold) and $\leqslant 92 \%$ (i.e., the British screening threshold) to identify severe hypoxaemia defined according to: 1) the Nocturnal Oxygen Therapy Trial (NOTT [1]) criteria; 2) $P_{\mathrm{aO}_{2}}$ $\leqslant 55 \mathrm{mmHg}$; or 3) $P_{\mathrm{aO}_{2}}<60 \mathrm{mmHg}$ regardless of oedema, haematocrit or ECG findings. From the same two cohorts, we constructed receiver operating characteristics (ROC) curves to determine the thresholds of saturation at which severe hypoxaemia is either ruled in or ruled out (i.e., false positive or negative results of $0 \%$ ). Finally, we used Cohort 3 to validate the results obtained from patients with COPD (Cohorts 1 and 2). All the analyses were performed using SAS version 9.4 (SAS Institute Inc, Cary, NC, USA).

\section{Results}

\section{Patients}

Patient characteristics are summarised in table 1. As expected, patients on LTOT (Cohort 2) had more severe hypoxaemia than those with nocturnal oxygen desaturation alone (Cohort 1). Although patients on LTOT were on average mildly hypercapnic, mean $\mathrm{pH}$ was normal (median: 7.42; interquartile range: 7.387.44), presumably indicating clinical stability when LTOT was initiated. Among the 240 patients who participated in the INOX trial (Cohort 1) and the 212 patients on LTOT (Cohort 2), 33 (14\%) and 56 (26\%) had a $P_{\mathrm{aO}_{2}}$ in the range of 56 to $59 \mathrm{mmHg}$, respectively.

Correlation between $\mathrm{S}_{\mathrm{aO}_{2}}$ and $\mathrm{S}_{\mathrm{pO}_{2}}$

$S_{\mathrm{aO}_{2}}$ and $S_{\mathrm{pO}_{2}}$ were moderately correlated (ICC: $0.43 ; 95 \%$ CI: $0.32-0.53 ; \mathrm{n}=240$, all from Cohort 1; supplementary Figure $1 S$ ). The mean \pm sD difference between the two measures was $0.6 \pm 2.0 \%$. The BlandAltman diagram indicates that the difference did not vary in a systematic pattern over the range of measurements (figure 1).

$\mathrm{S}_{\mathrm{aO}_{2}}$ to predict $\mathrm{P}_{\mathrm{OO}_{2}}$

The relation between $S_{\mathrm{aO}_{2}}$ and $P_{\mathrm{aO}_{2}}$ in patients with COPD (Cohort 1 and Cohort 2) and in the validation cohort (Cohort 3 ) is shown in figure 2. They represent in effect oxygen-haemoglobin dissociation curves. 


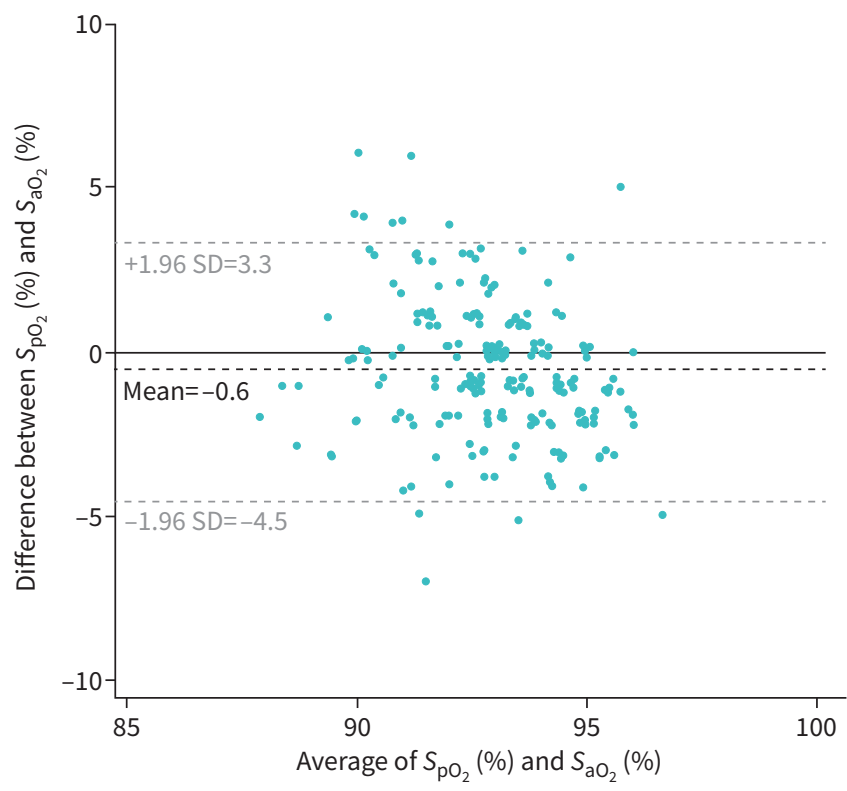

FIGURE 1 Bland-Altman diagram: agreement between pulse oximetry saturation $\left(\mathrm{S}_{\mathrm{pO}_{2}}\right)$ and arterial oxygen saturation $\left(\mathrm{SaO}_{2}\right)$ in the cohort of patients with isolated nocturnal oxygen desaturation $(n=240)$.

Cross-tabulation of $S_{\mathrm{aO}_{2}}$ and $P_{\mathrm{aO}}$ is presented in supplementary Tables $1 \mathrm{~S}$ and 2S. The dissociation curves and the cross-tabulation of $S_{\mathrm{aO}_{2}}$ and $P_{\mathrm{aO}_{2}}$ indicate the wide variability of $P_{\mathrm{aO}_{2}}$ for a given $S_{\mathrm{aO}_{2}}$, and conversely, the wide variability of $S_{\mathrm{aO}_{2}}$ for a given $P_{\mathrm{aO}_{2}}$. The significant effect of $\mathrm{pH}$ on the affinity of oxygen for haemoglobin is also demonstrated in supplementary Figure 2S.

Saturation to prescribe LTOT ( $\leqslant 88 \%)$ or to screen for patient selection ( $\leqslant 92 \%)$

Scatter plots of $S_{\mathrm{aO}_{2}}$ values in patients with severe hypoxaemia and those with isolated nocturnal desaturation are presented in figure 3. Among the 240 patients fulfilling the indication for nocturnal oxygen alone, four had a $S_{\mathrm{aO}_{2}} \leqslant 88 \%$ (false positive rate: $1.7 \%$ ). $S_{\mathrm{aO}_{2}}$ was $>88 \%$ in 84 of the 212 patients on LTOT (false negative rate for LTOT prescription: 39.6\%) (table 2). Table 2 also includes the false positive and false negative rates of $S_{\mathrm{aO}_{2}}$ at the threshold of $\leqslant 88 \%$ to detect severe hypoxaemia defined as $P_{\mathrm{aO}_{2}} \leqslant 55 \mathrm{mmHg}$ or $P_{\mathrm{aO}_{2}}<60 \mathrm{mmHg}$ (regardless of oedema, haematocrit and ECG findings). At the $S_{\mathrm{aO}_{2}}$ screening threshold of $\leqslant 92 \%, 4.7 \%$ (10 out of 212) of the truly hypoxaemic patients would not have been referred for further evaluation.

\section{Saturation thresholds to rule in or rule out the indication of LTOT}

From the ROC analysis, we determined in Cohorts 1 and 2 that a $S_{\mathrm{aO}_{2}}$ threshold of $\leqslant 87 \%$ rules in the indication of LTOT according to the NOTT criteria (i.e., false positive rate $=0 \%$ ) while a $S_{\mathrm{aO}_{2}}$ threshold of $\geqslant 96 \%$ rules out the indication of LTOT (i.e., false negative rate $=0 \%$ ) (figure 4 and supplementary Table 6S).

\section{Validation study}

The false positive and false negative rates in the determination of severe hypoxaemia $\left(P_{\mathrm{aO}} \leqslant 55 \mathrm{mmHg}\right.$ or $P_{\mathrm{aO}_{2}}<60 \mathrm{mmHg}$ ) at a $S_{\mathrm{aO}_{2}}$ threshold of $\leqslant 88 \%$ are shown in table 2 . We determined, from the ROC analysis, that a $S_{\mathrm{aO}_{2}} \leqslant 82 \%$ rules in severe hypoxaemia defined as $P_{\mathrm{aO}_{2}} \leqslant 55 \mathrm{mmHg}$ (i.e., false positive rate $=0 \%$ ), while a $S_{\mathrm{aO}_{2}} \geqslant 92 \%$ rules out severe hypoxaemia (i.e., false negative rate=0\%) (supplementary Table 7S). Similarly, a $S_{\mathrm{aO}_{2}} \leqslant 88 \%$ rules in severe hypoxaemia defined as $P_{\mathrm{aO}_{2}}<60 \mathrm{mmHg}$, while a $S_{\mathrm{aO}_{2}}$ $\geqslant 94 \%$ rules out severe hypoxaemia (supplementary Table $8 \mathrm{~S}$ ).

\section{Discussion}

Our findings question the validity of using oxygen saturation alone for the prescription of LTOT in COPD. First, as others [8-10], we observed that $S_{\mathrm{pO}_{2}}$ and $S_{\mathrm{aO}}$, were only moderately correlated. Also, in a recent study [18], the mean \pm SD difference between $S_{\mathrm{pO}_{2}}$ and $S_{\mathrm{aO}_{2}}\left(S_{\mathrm{aO}_{2}}-S_{\mathrm{pO}_{2}}\right)$ was remarkably similar to what we found ( $-0.6 \pm 2.6$ in Ekström's study versus $-0.6 \pm 2.0$ in ours). Second, although not measured with pulse oximetry, $\mathrm{pH}$ may have, as predicted by physiology, a significant effect on the relation between $S_{\mathrm{aO}_{2}}$ and 

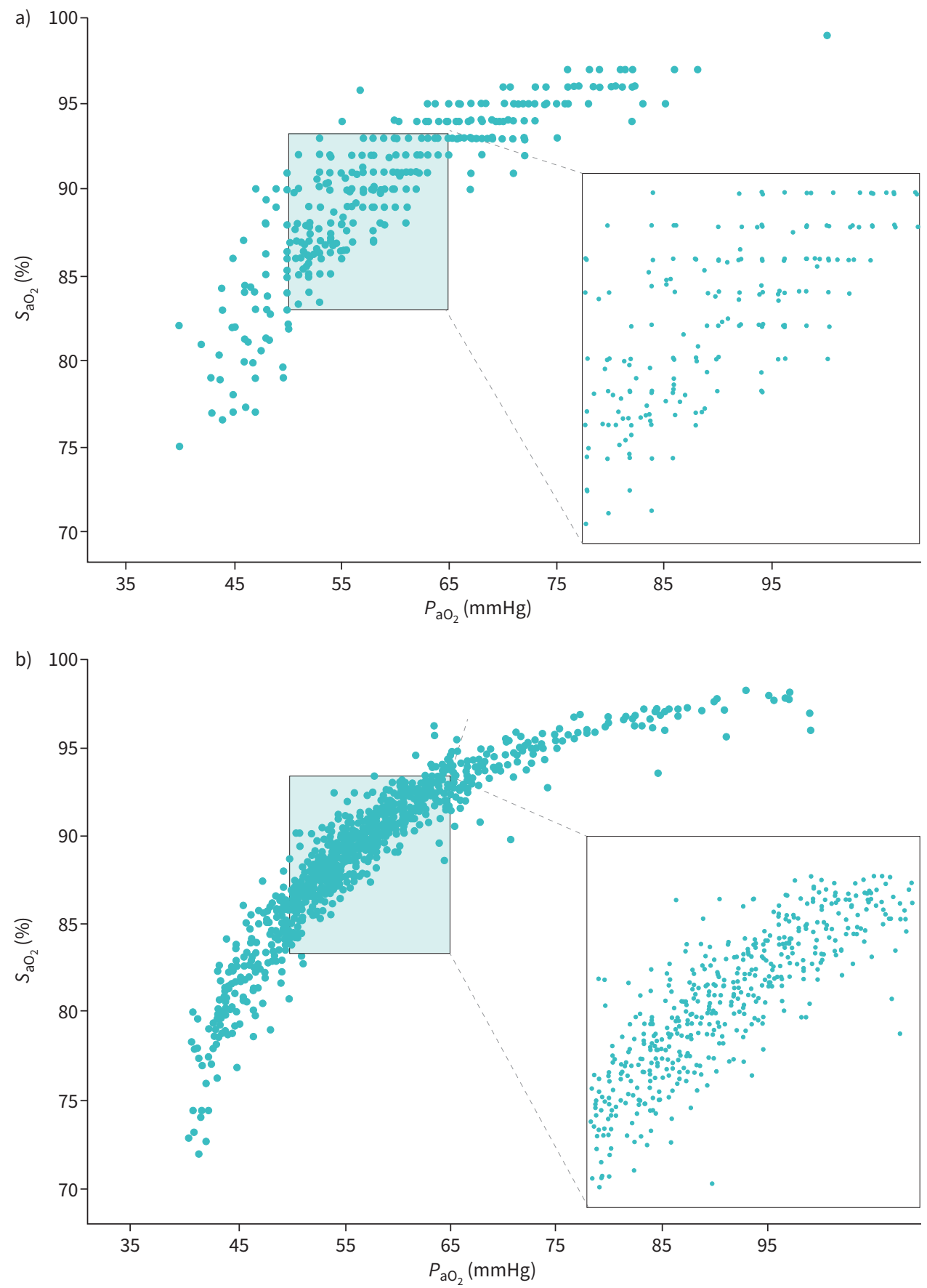

FIGURE 2 The relation between arterial oxygen saturation $\left(\mathrm{S}_{\mathrm{aO}_{2}}\right)$ and arterial oxygen tension $\left(P_{\mathrm{aO}}\right)$. a) Patients with COPD: $n=452$. b) Validation cohort: $n=848$.

$P_{\mathrm{aO}_{2}}$ as demonstrated by the dissociation curves (figure 1 and supplementary Figure 1S). Third, by using saturation alone, patients are much more often denied LTOT (false negative rate: 40\%) than they are prescribed LTOT when it is not indicated (false positive rate: 2\%). Fourth, our data suggest that the thresholds of $\leqslant 82 \%$ or $\geqslant 96 \%$ to either rule in or rule out the indication of LTOT may be considered. Even at these thresholds, several factors limit the accuracy of cutaneous pulse oximetry to determine whether LTOT is indicated. These factors include: 1) the precision of the currently available pulse oximeters [19]; 2) the potential for technical errors with their use; 3) the shape of the oxygen-haemoglobin dissociation curve, which may vary due to several unknown or unmeasured variables such as arterial blood $\mathrm{pH}$ and temperature [20]; and 4) the imperfect correlation between $S_{\mathrm{aO}_{2}}$ and $S_{\mathrm{pO}_{2}}$. 


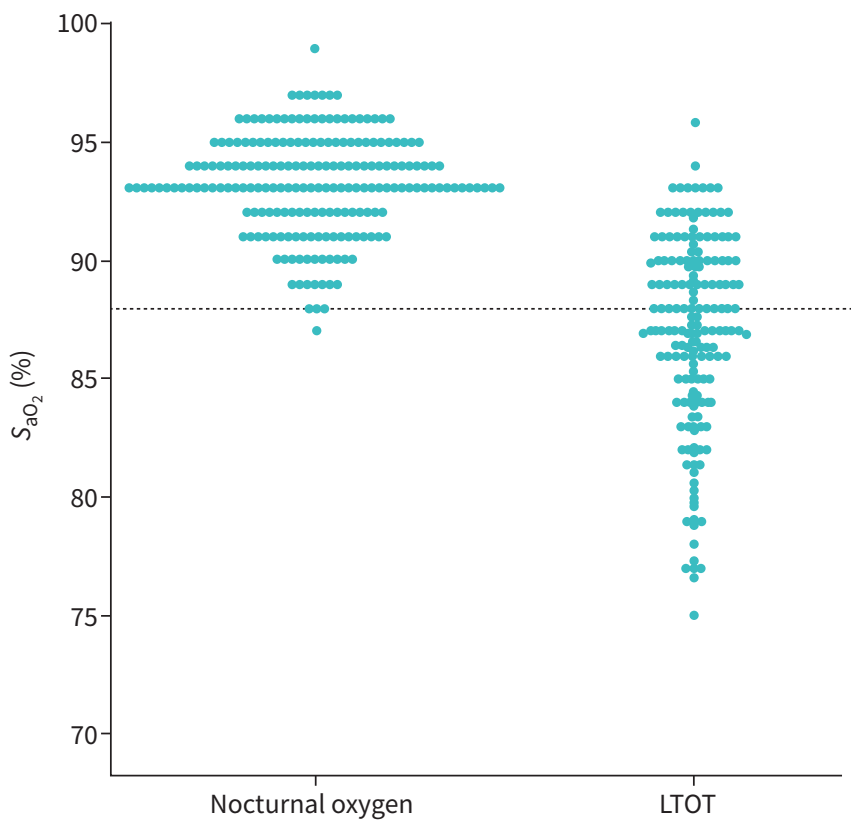

FIGURE 3 Scatter plot of the individual saturation values in patients on long-term oxygen therapy (LTOT) $(n=212)$ and those with isolated nocturnal oxygen desaturation $(n=240)$. The dashed line is located at the saturation threshold of $88 \%$. $\mathrm{S}_{\mathrm{aO}_{2}}$ : arterial oxygen saturation.

The reasons why arterial puncture to determine the indication of LTOT has been abandoned in several jurisdictions are unclear since other reports have also underlined the limitations of pulse oximetry [11, 21, 22]. Yet, arterial puncture, most often of the radial artery, is a safe and simple procedure. With the exception of local pain, bruising and haematoma, clinically significant complications are rare [23, 24]. Local pain may be decreased by local anaesthetic infiltration or the application of ice prior to the puncture [25, 26]. Topical anaesthetics do not seem to be effective to reduce pain [27]. The technique can be performed by several health professionals after minimal training [28-30]. Successful punctures may be obtained in almost $90 \%$ of cases [8]. The use of ultrasonography to guide arterial puncture of the radial artery does not seem to improve success rate compared with the conventional technique [31]. Blood gas analysers are found in most hospitals. Portable blood gas analysers are also available, with performance similar to that of conventional laboratory blood gas analysers [32]. Cost of arterial puncture is minimal and hardly an issue when the outcome is LTOT, a major cost driver in the management of COPD [33].

ABG measurement has its own limitations. It does not provide continuous data. Measurement errors are also possible. Air bubbles in syringe increases $P_{\mathrm{aO}}$, while elevated temperature and delayed analysis has the opposite effect [34, 35]. Transient hyperventilation occurring during arterial puncture may be sufficient to acutely increase $P_{\mathrm{aO}}$, a situation that will not reflect the chronic state of hypoxaemia [36]. Acute respiratory

TABLE 2 False positive and false negative rates of arterial oxygen saturation $\left(\mathrm{S}_{\mathrm{aO}_{2}}\right)$ at the threshold of $\leqslant 88 \%$ to identify severe hypoxaemia in COPD

\begin{tabular}{|c|c|c|c|c|}
\hline \multirow{2}{*}{$\begin{array}{l}\text { Severe hypoxaemia } \\
\text { defined as }\end{array}$} & \multicolumn{2}{|c|}{$S_{\mathrm{aO}_{2}} \leqslant 88 \%$ false positive rate } & \multicolumn{2}{|c|}{$S_{\mathrm{aO}_{2}} \leqslant 88 \%$ false negative rate } \\
\hline & $\begin{array}{c}\text { COPD } \\
\text { (Cohort 1+2) }\end{array}$ & $\begin{array}{l}\text { Validation } \\
\text { (Cohort 3) }\end{array}$ & $\begin{array}{c}\text { COPD } \\
\text { (Cohort 1+2) }\end{array}$ & $\begin{array}{l}\text { Validation } \\
\text { (Cohort 3) }\end{array}$ \\
\hline NOTT criteria [1] \% & $1.7^{\#}$ & & $39.6^{\#}$ & \\
\hline$P_{\mathrm{aO}_{2}} \leqslant 55 \mathrm{mmHg} \%$ & $4.7^{\circ}$ & $3.3^{+}$ & $21.9^{4}$ & $15.7^{+}$ \\
\hline$P_{\mathrm{aO}_{2}}<60 \mathrm{mmHg} \%$ & $0.5^{\circ}$ & $0^{+}$ & $45.4^{\circ}$ & $40.3^{+}$ \\
\hline
\end{tabular}

NOTT: Nocturnal Oxygen Therapy Trial; $P_{\mathrm{aO}}$ : arterial oxygen tension. \#: details are provided in supplementary Table 3S. ": details are provided in supplementary Table 4S. ${ }^{+}$: details are provided in supplementary Table 5S. 


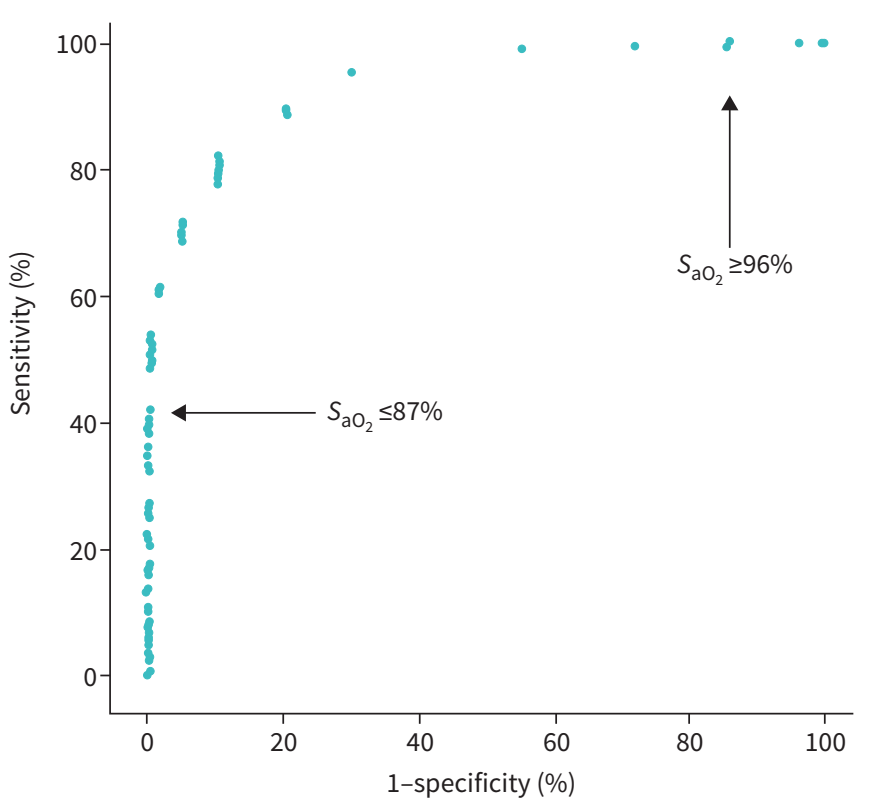

FIGURE 4 Receiver operating characteristics (ROC) curve: sensitivity and specificity of arterial oxygen saturation $\left(\mathrm{S}_{\mathrm{aO}_{2}}\right)$ at varying thresholds to detect severe hypoxaemia (arterial oxygen tension $\left(P_{\mathrm{aO}_{2}}\right) \leqslant 55 \mathrm{mmHg}$ or $P_{\mathrm{aO}_{2}}$ of 56 to $59 \mathrm{mmHg}$ with evidence of cor pulmonale or erythrocythaemia) at the level to which long-term oxygen therapy (LTOT) is indicated according to the Nocturnal Oxygen Therapy Trial (NOTT) criteria. This analysis combined Cohorts 1 and 2 (i.e., the two cohorts of patients with COPD). The arrows indicate the saturation thresholds at which the false positive rate $\left(\mathrm{S}_{\mathrm{aO}_{2}} \leqslant 87 \%\right)$ and false negative rate $\left(\mathrm{S}_{\mathrm{aO}_{2}} \geqslant 96 \%\right)$ are null.

alkalosis on ABG measurement must alert clinicians to this possibility. The analysis of capillary blood, either arterialised or not, has been proposed as an alternative to ABG measurement. At least two separate meta-analyses comparing capillary and ABG have been published [37, 38]. Richter et al. [38] developed regression models to predict $\mathrm{ABG}$ (including $P_{\mathrm{aO}_{2}}$ ) from capillary blood gas values. The authors found excellent predictability of the models and emphasised the potential of capillary blood gases in the management of acute respiratory conditions, without mentioning chronic conditions. ZAVORSKY and colleagues [37] found that earlobe sampling better predicts $P_{\mathrm{aO}_{2}}$ (adjusted $\mathrm{r}^{2}=0.88$, mean bias $=3.8 \mathrm{mmHg}$ compared to arterial) than fingertip sampling (adjusted $r^{2}=0.48$, mean bias $=11.5 \mathrm{mmHg}$ compared to arterial). The authors concluded that, in most circumstances, sampling blood from earlobe but not from the fingertip may be, in some circumstances, appropriate as a replacement for $P_{\mathrm{aO}}$, unless precision is required.

A limitation of our study is that we determined the false positive and negative rates of saturation to identify severe hypoxaemia as well as the saturation thresholds to rule in or rule out the indication of LTOT on the basis of $S_{\mathrm{aO}_{2}}$ (not $S_{\mathrm{pO}_{2}}$ ). Also, ABGs in our cohorts of patients with COPD were obtained from different analysers. In this regard, a study has found that differences in $P_{\mathrm{aO}}$ values from measurements performed on different blood gas analysers in different laboratories are negligible [39]. Temperature, a significant factor affecting the binding of oxygen to haemoglobin, was not taken into account.

\section{Conclusion}

Our study confirmed that $S_{\mathrm{aO}_{2}}$ and $S_{\mathrm{pO}_{2}}$ are only loosely correlated. We found that several patients who qualify for LTOT would be denied treatment using a $S_{\mathrm{aO}_{2}}$ prescription threshold $\leqslant 88 \%$ or a screening threshold $\leqslant 92 \%$. We therefore conclude that oxygen saturation $\left(S_{\mathrm{aO}_{2}}\right.$, and a fortiori $\left.S_{\mathrm{pO}_{2}}\right)$ is not an adequate replacement of direct $P_{\mathrm{aO}_{2}}$ measurement for prescribing LTOT or for screening for further assessment of eligibility for LTOT. If chronic hypoxaemia is suspected, patient evaluation should rely on ABG measurement. This practice has its own limitations, since it represents a static and instantaneous measure that may not reflect patients' long-term oxygenation status. However, it has the merit to be aligned with the current indications for LTOT that were defined by the NOTT and the British Medical Research Council trial. 
Author contributions: Conception and design: Y. Lacasse, F. Sériès and F. Maltais; acquisition of data: S. Thériault, B. St-Pierre and S. Bernard; analysis: Y. Lacasse and H.J. Bernatchez; interpretation of data: Y. Lacasse, F. Sériès, H.J. Bernatchez and F. Maltais; writing: Y. Lacasse, S. Thériault, F. Sériès and F. Maltais.

Provenance: Submitted article, peer reviewed.

Conflict of interest: None declared.

Support statement: This study was supported by the Groupe de recherche en santé respiratoire de l'Université Laval. Funding information for this article has been deposited with the Crossref Funder Registry.

\section{References}

1 Nocturnal Oxygen Therapy Trial Group. Continuous or nocturnal oxygen therapy in hypoxemic chronic obstructive lung disease: a clinical trial. Ann Intern Med 1980; 93: 391-398.

2 Report of the Medical Research Council Working Party. Long term domiciliary oxygen therapy in chronic hypoxic cor pulmonale complicating chronic bronchitis and emphysema. Lancet 1981; 1: 681-686.

3 Global Initiative for Chronic Obstructive Lung Disease (GOLD). Global Strategy for the Diagnosis, Management and Prevention of COPD. 2018. http://goldcopd.org/ Date last accessed: 19 March 2020.

4 US Centers for Medicare and Medicaid Services. Medicare learning network. Home Oxygen Therapy. www. cms.gov/Research-Statistics-Data-and-Systems/Computer-Data-and-Systems/Electronic-Clinical-Templates/ DMEPOS-Templates/DMEPOS-Home-Oxygen-Therapy Date last updated: 11 March 2021.

5 Jacobs SS, Krishnan JA, Lederer DJ, et al. Home oxygen therapy for adults with chronic lung disease. An official American Thoracic Society clinical practice guideline. Am J Respir Crit Care Med 2020; 202: e121-ee41.

6 Lacasse Y, Bernard S, Maltais F. Eligibility for home oxygen programs and funding across Canada. Can Respir J 2015; 22: 324-330.

7 Hardinge M, Annandale J, Bourne S, et al. British Thoracic Society guidelines for home oxygen use in adults. Thorax 2015; 70: Suppl. 1, i1-43.

8 Jensen LA, Onyskiw JE, Prasad NG. Meta-analysis of arterial oxygen saturation monitoring by pulse oximetry in adults. Heart Lung 1998; 27: 387-408.

9 Amalakanti S, Pentakota MR. Pulse oximetry overestimates oxygen saturation in COPD. Respir Care 2016; 61: 423-427.

10 Lipnick MS, Feiner JR, Au P, et al. The accuracy of 6 inexpensive pulse oximeters not cleared by the Food and Drug Administration: the possible global public health implications. Anesth Analg 2016; 123: 338-345.

11 Carlin BW, Clausen JL, Ries AL. The use of cutaneous oximetry in the prescription of long-term oxygen therapy. Chest 1988; 94: 239-241.

12 Lacasse $\mathrm{Y}$, Series $\mathrm{F}$, Corbeil F, et al. Randomized trial of nocturnal oxygen in chronic obstructive pulmonary disease. N Engl J Med 2020; 383: 1129-1138.

13 Lacasse Y, Series F, Vujovic-Zotovic N, et al. Evaluating nocturnal oxygen desaturation in COPD - revised. Respir Med 2011; 105: 1331-1337.

14 Burtis C, Ashwood E, Bruns D. Tietz Textbook of Clinical Chemistry and Molecular Diagnostics, 5th Edn. Philadelphia, PA, Saunders, 2012; pp. 825-826.

15 Bland JM, Altman DG. Statistical methods for assessing agreement between two methods of clinical measurement. Lancet 1986; 1: 307-310.

16 Astrup P, Engel K, Severinghaus JW, et al. The influence of temperature and $\mathrm{pH}$ on the dissociation curve of oxyhemoglobin of human blood. Scand J Clin Lab Invest 1965; 17: 515-523.

17 Cleveland WS, Devlin SJ. Locally weighted regression: an approach to regression analysis by local fitting J Amer Statist Assoc 1988; 83: 596-610.

18 Ekstrom M, Engblom A, Ilic A, et al. Calculated arterial blood gas values from a venous sample and pulse oximetry: clinical validation. PLoS One 2019; 14: e0215413.

19 Nitzan M, Romem A, Koppel R. Pulse oximetry: fundamentals and technology update. Med Devices (Auckl) 2014; 7: 231-239.

20 Duffin J, Fisher J. Unknown in vivo factors influencing the oxygen dissociation curve? Respir Physiol Neurobiol 2013; 188: 81.

21 Elborn JS, Finch MB, Stanford CF. Non-arterial assessment of blood gas status in patients with chronic pulmonary disease. Ulster Med J 1991; 60: 164-167.

22 Roberts CM, Bugler JR, Melchor R, et al. Value of pulse oximetry in screening for long-term oxygen therapy requirement. Eur Respir J 1993; 6: 559-562.

23 Giner J, Casan P, Belda J, et al. Pain during arterial puncture. Chest 1996; 110: 1443-1445.

24 Gillies ID, Morgan M, Sykes MK, et al. The nature and incidence of complications of peripheral arterial puncture. Anaesthesia 1979; 34: 506-509. 
Lightowler JV, Elliott MW. Local anaesthetic infiltration prior to arterial puncture for blood gas analysis: a survey of current practice and a randomised double blind placebo controlled trial. $J$ R Coll Physicians Lond 1997; 31: 645-646.

26 Haynes JM. Randomized controlled trial of cryoanalgesia (ice bag) to reduce pain associated with arterial puncture. Respir Care 2015; 60: 1-5.

27 Tran NQ, Pretto JJ, Worsnop CJ. A randomized controlled trial of the effectiveness of topical amethocaine in reducing pain during arterial puncture. Chest 2002; 122: 1357-1360.

28 Sackner MA, Avery WG, Sokolowski J. Arterial punctures by nurses. Chest 1971; 59: 97-98. Serbin AL. Arterial punctures by pulmonary function laboratory technicians. Ariz Med 1972; $29: 860-861$.

Fagan MJ, Cece R. Using respiratory therapists to teach arterial puncture for blood gas procedures to third-year medical students. Acad Med 1999; 74: 594-595.

31 Laursen CB, Pedersen RL, Lassen AT. Ultrasonographically guided puncture of the radial artery for blood gas analysis: a prospective, randomized controlled trial. Ann Emerg Med 2015; 65: 618-619.

32 Sediame S, Zerah-Lancner F, d'Ortho MP, et al. Accuracy of the i-STAT bedside blood gas analyser. Eur Respir J 1999; 14: 214-217.

33 Foo J, Landis SH, Maskell J, et al. Continuing to confront COPD international patient survey: economic impact of COPD in 12 countries. PLoS One 2016; 11: e0152618.

34 Biswas CK, Ramos JM, Agroyannis B, et al. Blood gas analysis: effect of air bubbles in syringe and delay in estimation. Br Med J (Clin Res Ed) 1982; 284: 923-927.

35 Madiedo G, Sciacca R, Hause L. Air bubbles and temperature effect on blood gas analysis. J Clin Pathol 1980; 33: $864-867$.

36 Cinel D, Markwell K, Lee R, et al. Variability of the respiratory gas exchange ratio during arterial puncture. Am Rev Respir Dis 1991; 143: 217-218.

37 Zavorsky GS, Cao J, Mayo NE, et al. Arterial versus capillary blood gases: a meta-analysis. Respir Physiol Neurobiol 2007; 155: 268-279.

38 Richter S, Kerry C, Hassan N, et al. Capillary blood gas as a substitute for arterial blood gas: a meta-analysis. Br J Hosp Med (Lond) 2014; 75: 136-142.

39 Kampelmacher MJ, van Kesteren RG, Winckers EK. Instrumental variability of respiratory blood gases among different blood gas analysers in different laboratories. Eur Respir J 1997; 10: 1341-1344. 